terrestrial isopods. As an author, moreover, Dr. Baldwin has achieved remarkable success. His "Introduction to Comparative Biochemistry" was well received, and later a larger "Dynamic Aspects of Biochemistry" has been widely welcomed as one of the most valuable modern books available for students of the subject. More recently, he was joint editor of the volume of addresses by the late Sir Frederick Gowland Hopkins, and of material about his life and influence, entitled "Fopkins and Biochemistry". A copy of this was received by each member of last year's International Congress of Biochemistry, not all of whom, however, can have realized the enormous amount of selfless work which Dr. Baldwin put in as joint secretary-general of the Congress, and which contributed so much to its success.

\section{National Institute of Sciences of India: New Fellows}

Aт a meeting of the Council of the National Institute of Sciences of India held at Poona on January 1, the following fellows were elected. Ordinary Fellows: Dr. D. P. Antia, development officer, Ministry of Industry and Supply, New Delhi ; Dr. F. C. Auluck, reader in physics, University of Delhi ; Dr. P. L. Bhatnagar, head of the Department of Mathematics, St. Stephen's College, and reader in mathematics, University of Delhi; Dr. K. Biswas, in charge of duties of director at the Herbarium, Royal Botanic Gardens, Sibpur, Calcutta ; Dr. J. P. Bose, officer in charge, Department of Biochemistry and Diabetes, School of Tropical Medicine, Calcutta; Dr. R. N. Chaudhuri, professor of tropical medicine, School of Tropical Medicine, Calcutta; Dr. V. M. Ghatage, assistant professor of aeronautical engineering, Indian Institute of Science, Bangalore; Dr. H. Gupta, senior lecturer in mathematics, Government College, Hoshiarpur; Dr. T. J. Job, chief research officer, Central Inland Fisheries Research Station, Manirampur, Barrackpore; Prof. R. S. Krishnan, professor of physics, Indian Institute of Science, Bangalore; Prof. M. C. Nath, Chitnavis professor and head of the Department of Biochemistry, University of Nagpur; Dr. H. N. Ray, research officer (protozoology), Indian Veterinary Research Institute, Mukteswar-Kumaun; Dr. M. R. Sahni, superintending geologist, Geological Survey of India, Calcutta; Dr. A. Sreenivasan, lecturer in foods and drugs, Department of Chemical Technology, University of Bombay; and Dr. R. S. Vasudeva, plant pathologist, Indian Agricultural Research Institute, New Delhi. Honorary Fellows: Prof. P. Debye, professor of chemistry, Cornell University; Prof. M. von Laue, professor of theoretical physics, Univer. sity of Berlin; Prof. M. Siegbahn, professor of physics, University of Uppsala; and Prof. E. Schrödinger, professor of physies, Institute for Advanced Studies, Dublin.

\section{Endeavour Prizes}

As a contribution to the meeting of the British Association for the Advancement of Science to be held at Birmingham in September 1950, Imperial Chemical Industries, Ltd., publishers of the quarterly scientific review Endeavour, have offered the sum of eighty-five guineas to be awarded as prizes for essays submitted on a scientific subject. As the primary purposes of these awards is to stimulate younger scientific workers to take an interest in the work of the British Association, and to raise the literary standard of scientific writing, the competition is restricted to those who are not more than twenty-five years of age on June 25, 1950. Three prizes will be awarded : a first prize of fifty guineas, a second prize of twenty-five guineas, and a third prize of ten guineas. The subjects for the essays are as follows : (1) Modern Techniques in Astrophysics; (2) Phenomena at Low Temperatures ; (3) The Literature of Science; (4) Radioactive Tracers; (5) Metallic Corrosion: (6) Macromolecules ; (7) The History and Significance of Common Salt ; (8) The Scientific Method; (9) The Mechanism of Heredity; (10) The Biological Significance of Trace Elements; (11) Industrial Applications of Biology; (12) The Earth's Crust. The latest date for receipt of entries is June 26. Further information can be obtained from: The Assistant Secretary, British Association for the Advancement of Science, Burlington House, Piccadilly, London, W.1.

\section{Supply and Demand for Chemists}

The pamphlet "Present and Future Supply and Demand for Persons with Professional Qualifications in Chemistry" (London: H.M. Stationery Office. 6d. net) is a report prepared at the request of the Minister of Labour and National Service by a sub-committee under the chairmanship of Lord Hankey and comprising representatives of many interested bodies. Evidence was taken from various organisations, and the conclusions reached are therefore based on comprehensive information. It is stated that the universities in Great Britain are finding difficulty in recruiting academic staff of the requisite quality to attend to the needs of the greatly increased number of science graduates. Pressure on accommodation is also serious. The capacity of schools to prepare university entrants is limited. On the industrial side, it is stated that many entrants have insufficient enthusiasm for the practical applications of science, and that the needs of the process side should be kept in mind. Recruitment in physical chemistry, biochemistry and specialized analytical chemistry is found difficult, and many potential physical chemists are deterred from taking up the subject because of insufficient training in mathematics. The question of supply and demand in future was most carefully considered, and the conclusion is reached that the expanded number of chemists now undergoing training is not in excess of those likely to be required in the years ahead. The university institutions in Great Britain, which have been doing extremely well in carrying out the recommendations of the Barlow Report with temporary facilities, should have their requirements filled on a more satisfactory basis. The implications of this and other reports in the same series are discussed in the leading article on p. 125 of this issue of Nature.

\section{Nuffield Foundation Fellowships}

BECAUSE of the increasing size and complexity of administration, the Nuffield Foundation has been turning its attention to the need to promote the training of administrators. The Treasury has accepted an offer by the Foundation to provide $£ 22,500$ for a five-year experimental scheme of travelling fellow. ships for members of the Home Civil Service. The purpose of the scheme is to enable Civil servantsnormally of the rank of principal or assistant secretary, or the equivalent in the professional, scientific and departmental classes-to gain first-hand acquaintance with the administration, problems, experiences and opportunities of the overseas parts of the British 